\title{
DELIBERAÇÕES LEGISLATIVAS E A SOBRE-REPRESENTAÇÃO NA CÂMARA DOS DEPUTADOS
}

André Felipe de Carvalho e Silva*

Marcelo Barroso Lacombe*

\begin{abstract}
Resumo: Este artigo analisa a questão das distorções na representação dos estados na Câmara dos Deputados do Brasil. Considerando-se a sobre-representação dos estados, é montado um cenário ajustado à representação ideal para simulação dos resultados das deliberações tomadas na $51^{\text {a }}$ Legislatura de modo a identificar em que gradação se dá a influência desta distorção na Câmara dos Deputados.
\end{abstract}

Palavras-chave: Representação política. Sobre-representação. Sub-representação. Câmara dos Deputados. Representação proporcional.

Abstract: This article analyses the actual distribution of Lower House seats among Brazilian states. Then, this article presents a model of seat distribution focused on over-representation that is closer to the actual geographic distribuition of voters. Finally, it compares actual delibaration results in the 51th Congress with those simulated in the model distribution.

Keywords: Political representation. Over-representation. Sub-representation, House of Representatives. Proporcional representation.

\section{Desproporcionalidade na Câmara dos Deputados}

Um dos principais problemas dos sistemas representativos nas democracias é a não proporcionalidade entre a população de uma determinada circunscrição eleitoral e a quantidade de representantes no Parlamento. No Brasil, verifica-se a ocorrência de duas vertentes desse fenômeno,

Especialista em Processo Legislativo pelo Cefor/Câmara dos Deputados. andre.felipe.@camara.gov.br .* Mestre em Ciência Política. marcelo.lacombe@ @amara.gov.br 
a sobre-representação, que favorece os estados pouco povoados, e a sub-representação, que desfavorece os estados mais populosos na distribuição de cadeiras na Câmara dos Deputados.

A alocação desproporcional de assentos na Câmara dos Deputados entre os estados é fator presente na história institucional brasileira e tema constante de uma série de autores. São notórias as diferenças de opinião sobre a manutenção ou não do cenário que se verifica na representação dos Deputados Federais. Um dos precursores desse debate, Miguel Reali, ao analisar os efeitos das distorções na representação da Câmara dos Deputados a partir das Constituintes de 1934 e 1946, considerou injustificável que "considerações peculiares ao sistema federalista se insinuem na problemática da representação popular, influindo na composição da Câmara dos Deputados" (REALI, 1959, p. 27).

Serra (1997), por sua vez, utiliza-se de argumento que acompanha boa parte dos que divergem do cenário atual: as atribuições do Senado e da Câmara dos Deputados são de representar a federação e a população, respectivamente. A partir daí, infere que a definição de número idêntico de senadores para representar cada estado objetiva evitar que estados mais populosos prevaleçam sobre outros. Assim, assevera que a representação na Câmara Federal deveria ser proporcional à população dos estados.

Outros autores, como Márcia Soares e Luiz Lourenço (2002), questionam a representação estritamente proporcional em termos de indivíduo/voto sob o juízo de que, dessa forma, interesses federativos, territorialmente relevantes, mesmo que minoritários, não teriam possibilidade de se fazer representar. Refutam, adicionalmente, o argumento de que caberia constitucionalmente ao Senado a representação dos estados e à Câmara a representação dos indivíduos, ao ponderar que existe sobreposição das atribuições das duas Casas. Ana Luíza Backes (1998), ao analisar uma série de fatores associados ao processo legislativo federal, reforça tal posicionamento argumentando que as atribuições das duas Casas são bastante semelhantes, ao contrário do senso comum que restringe as atribuições do Senado Federal a questões federativas.

Essa "flexibilização" em relação ao princípio da igualdade eleitoral instiga uma reflexão sobre a necessidade de se compensar disparidades políticas. Conforme Katz (1997 apud BACKES, 1998), são dois os principais instrumentos constitucionais usados para acomodar diferenças entre membros de uma federação: a sobre-representação de unidades menores e a garantia de autonomia em certas áreas especialmente sensíveis da política pública, normalmente associadas à língua, educação, religião e cultura.

Em consonância com tal pensamento, alguns autores consideram legítima e necessária a ocorrência de distorções. A compensação das disparidades seria feita por meio do fortalecimento de grupos minoritários. Tudo condicionado à manutenção da capacidade de governar por parte dos 
grupos majoritários. Santos (1987 apud BACKES, 1998) considera que a sobre-representação de estados pequenos, ao contrário de desrespeitar o equilíbrio federativo, seria uma forma de compensação das diferenças.

Outro argumento recorrente, utilizado por críticos das distorções de representação que seguiram Reali, é a associação entre subdesenvolvimento econômico e sobre-representação. Sob o ponto de vista de Luiz Navarro de Britto (1965), esses são fatores determinantes para a manutenção do coronelismo nessas regiões. Opinião corroborada por Dillon Soares, que vai além, afirmando que a inadequação na representação de diversos grupos sociais no País, causada pelo atual sistema eleitoral, obstaculiza uma série de reformas necessárias:

Esta desproporção prejudicou a maioria da população dos menos desenvolvidos, aumentando o poder das elites dirigentes da região, cujos interesses entram em choque com os da maioria da população. Efetivamente, ao aumentar artificialmente a representação política de uma cultura política tradicional, atrasada dominada pelos líderes locais, freqüentemente latifundistas, proprietários rurais, coronéis de todos os tipos, ou pessoas de sua escolha e confiança terminou por prejudicar a maioria da população dessas áreas (SOARES, 1973, p. 27).

Bolívar Lamounier contesta a afirmação de Dillon Soares de que os coronéis têm votação concentrada: "o suposto discutível é que os coronéis, e somente eles, têm sua votação espacial concentrada" (LAMOUNIER, 1982, p. 12, grifo do autor). Octaciano Nogueira também questiona esse ponto de vista:

Resta à crença de que os eleitores das regiões subdesenvolvidas são mais facilmente manipuláveis, porque sujeitos a influência de favores econômicos ou promessas e recompensas. Na prática, isto se traduziria na certeza da sobrevivência dos chamados currais eleitorais, representados pelos grotões em que os instrumentos de controle e pressão sobre os eleitores são maiores e mais efetivos. Isto se tem pretendido provar, também empiricamente, pela concentração de votos nos candidatos que tiram desses colégios eleitorais a maioria dos sufrágios necessários à sua eleição (NOGUEIRA, 1997, p. 151).

Nogueira fundamenta seu posicionamento em estudos realizados por Nelson Rojas de Carvalho (1996 apud NOGUEIRA, 1997) acerca da concentração e dispersão geográfica do voto no País. Carvalho, a partir de levantamento feito sobre a distribuição dos votos dados aos deputados, afirma que está no Sudeste, e não no Nordeste, um maior índice (67\%) de deputados com votação concentrada em poucos municípios, o que sugeriria a ocorrência de currais nessas regiões.

Para refutar o argumento de que compensar o desequilíbrio distribuindo desigualmente poder e influência política é algo negativo e que contribui para perpetuar o atraso, Nogueira afirma: "não há nenhuma evidência empírica que permita relacionar condições sociais, poder econômico ou desenvolvimento cultural com comportamento eleitoral". Escreve ainda que "a percentagem de cidadãos relativamente atentos e informados em política não varia de maneira acentuada, inclusive quando essas condições [de pobreza e analfabetismo] variam” (NOGUEIRA, 1997, p. 148).

Outra questão relevante diz respeito à sobre-representação de regiões e seus efeitos sobre a 
distribuição de recursos federais. Haveria favorecimento a regiões politicamente sobrerepresentadas? Edward L. Gibson (2003) sugere que sim. Em trabalho que analisa quatro grandes estados federados, Estados Unidos da América, México, Brasil e, mais especificamente, a Argentina, o autor sugere que, nos dois últimos, onde a Câmara dos Deputados apresenta sobrerepresentação política, existe uma "realocação de fundos partilhados da receita federal e de gastos discricionários que beneficiam estados sobre-representados" (GIBSON, 2003, p. 119) e conclui que considerações de políticas públicas nessas federações teriam menor influência que a sobrerepresentação política na distribuição não proporcional de recursos públicos. Diz o autor:

Se o Congresso desempenha um papel essencial na determinação desses fluxos, a sobrerepresentação pode induzir realocações dos gastos federais influenciadas pelo Legislativo, onde os próprios estados sobre-representados efetuam tais realocações graças a sua alavancagem nas comissões de orçamento (idem).

Conclui, ainda, que "A Câmara de Deputados, e não o Senado é a força propulsora por trás da realocação das transferências federais em favor de estados e províncias sobre-representadas" (idem).

Backes, por sua vez, apresenta posição discordante quanto à relação entre recursos públicos e representação política: "O Controle do Parlamento sobre os recursos orçamentários na verdade é restrito: apenas cerca de 5\% do total de recursos vêm sendo remanejados pelos parlamentares. Além disso, a lei orçamentária no Brasil é apenas autorizativa, não obriga à execução" (BACKES, 1998, p.139, grifo da autora).

Diversas são as propostas com fito de tornar a distribuição de cadeiras na Câmara mais proporcional, entretanto algumas carecem de viabilidade prática. Como esclarece Lamounier, caso seja aplicado "um critério de rigorosa proporcionalidade em relação à população de cada Estado, de duas uma: ou teremos os Estados muito pequenos representados por apenas um ou dois deputados, ou mantemos um mínimo razoável, e nesse caso a proporcionalidade nos forçará a aceitar uma Câmara de dimensões mastodônticas" (LAMOUNIER, 1987, p. 23).

\section{Simulação das Deliberações}

Compelido pelas considerações anteriores, há que se questionar: poderiam essas distorções influir decisivamente na deliberação de matérias pela Câmara dos Deputados? Isto é, as leis poderiam ser diferentes caso fossem utilizados critérios rigorosamente proporcionais para definir a representação? A fim de responder objetivamente a essa indagação, será avaliado se os resultados das votações ocorridas teriam sido diferentes caso a composição da Casa fosse rigorosamente proporcional. 
Para viabilização de tal objetivo, delimitou-se o escopo da avaliação a uma pequena amostra das deliberações ocorridas na Casa. Optou-se pela 51 ${ }^{a}$ Legislatura visto haver disponibilidade de dados em formato eletrônico e ser ela a mais recente dentre as já concluídas. Os resultados das votações ocorridas nessa legislatura serão comparados com simulações construídas por meio da elaboração de um cenário ajustado à representação ideal, a fim de identificar objetivamente em que gradação se dá a influência da sobre-representação na Câmara dos Deputados.

Serão excluídos da análise os efeitos que eventualmente a sub-representação teria sobre os resultados das votações, em função da complexidade para adoção de uma estratégia objetiva para inferir resultados a partir da eliminação de tal distorção, cenário viável se a abordagem se limitar à sobre-representação.

Apesar das considerações anteriores, são encontradas na literatura abordagem alternativa, como a oferecida por Dillon Soares (1984 apud BACKES, 1988) que analisa a votação, em 1984, da Emenda Dante de Oliveira que instituía o voto direto para Presidência da República. O raciocínio do autor parte do seguinte princípio: faltaram 22 votos para a aprovação da emenda. Dos 60 deputados paulistas, 75\% votaram favoravelmente. Caso o Estado de São Paulo tivesse representação proporcional à sua população, o que agregaria àquela bancada mais 45 deputados, e ocorresse o mesmo padrão de comportamento ao votar, seriam mais 33 votos favoráveis à Emenda, promovendo sua aprovação.

Para a construção da simulação que se realiza neste trabalho, foi indispensável a fixação de alguns pontos:

a) Restringiu-se a simulação às deliberações tomadas pelo Plenário da Câmara dos Deputados;

b) Foram utilizadas como insumo as votações nominais realizadas via painel eletrônico, visto as secretas não terem serventia para a análise;

c) Fez-se uso do quantitativo de deputados eleitos para 51 a Legislatura (513) como referência para fixação do quantitativo de assentos à qual fazia jus cada Estado;

d) Ao se delimitar os ajustes da representação às bancadas dos estados sobre-representados, os votos adicionais que seriam referentes aos estados sub-representados não foram computados nas simulações, implicando a impossibilidade do número de votantes alcançar quinhentos e treze (513), o quantitativo de cadeiras da legislatura em questão.

e) Ao se utilizar critérios estritamente proporcionais, fez-se necessária a exclusão dos votos oriundos de alguns representantes de estados sobre-representados, especificamente aqueles que, de acordo com as regras eleitorais vigentes à época, não poderia representar tal unidade federativa; 
f) Para os deputados suplentes, só foram considerados válidos os votos dados em substituição a vagas que pelos critérios proporcionais caberiam àquele Estado;

A distribuição de assentos na $51^{a}$ legislatura foi regida pela Constituição de 1988 que, após a Resolução do TSE de nº 14.235 de 1994, definiu que a Câmara dos Deputados seria composta por 513 parlamentares assim distribuídos:

Tabela $1-51^{\text {a }}$ Legislatura

\begin{tabular}{|c|c|c|c|}
\hline UF & Representacão Oficial & UF & Representacão Oficial \\
\hline AC & 8 & PB & 12 \\
\hline AL & 9 & PE & 25 \\
\hline AM & 8 & PI & 10 \\
\hline AP & 8 & PR & 30 \\
\hline BA & 39 & RJ & 46 \\
\hline CE & 22 & RN & 8 \\
\hline DF & 8 & RO & 8 \\
\hline ES & 10 & RR & 31 \\
\hline GO & 17 & RS & 16 \\
\hline MA & 18 & SC & 8 \\
\hline MG & 53 & SE & 8 \\
\hline MS & 8 & SP & \\
\hline MT & 8 & TO & \\
\hline PA & 17 & & \\
\hline
\end{tabular}

Fonte: Seção de Documentos Audiovisuais da Câmara dos Deputados (CEDI).

Os Deputados Federais àquela época, assim como hoje, são eleitos pelo sistema proporcional regulamentado pelos artigos 106 a 111 do Código Eleitoral Brasileiro.

\section{Simulação da Representação}

Para se construir a presumida distribuição de cadeiras, primeiramente, recorreu-se aos levantamentos demográficos realizados pelo IBGE. A partir daí, dividiram-se as bancadas na proporção da população residente em cada Estado. Motivado pelo critério aritmético de aproximação (arredondamento para o inteiro mais próximo), utilizado nos cálculos para disposição dos assentos, o quantitativo total de deputados para essa legislatura foi arredondado em 511.

A partir da tabela anterior, os resultados eleitorais que definiram cada uma das bancadas de estados sobre-representados foram reavaliados, a fim de se adequarem à configuração proposta. Aplicou-se o que determinava o Código Eleitoral para definição dos representantes de cada um dos estados sobre-representados. Para tal, foi indispensável a utilização dos dados relativos aos resultado eleitorais de 1998 disponibilizados pelo Tribunal Superior Eleitoral.

Conforme explicação anterior, as cadeiras adicionais que caberiam aos estados subrepresentados não foram consideradas nas votações, haja vista não ter se procedido a nenhuma definição de padrão de comportamento nas votações. Na prática, a recusa em simular os votos 
adicionais dos estados sub-representados implica reduzir o quantitativo de votantes utilizados na simulação a 466 , conforme tabela abaixo.

\section{Tabela 2 - Total máximo de votos computados na simulação}

\begin{tabular}{|c|c|c|c|c|}
\hline UF & Representação Oficial & Representação Proporcional & Votos da Simulação & OBS \\
\hline$\overline{A C}$ & 8 & 2 & 2 & $\overline{k \star \star}$ \\
\hline$\overline{A L}$ & 9 & 9 & 9 & 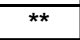 \\
\hline$\overline{\mathrm{AM}}$ & 8 & 8 & 8 & 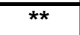 \\
\hline $\mathbf{A P}$ & 8 & 1 & 1 & 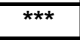 \\
\hline BA & 39 & 40 & 39 & * \\
\hline CE & 22 & 22 & 22 & 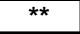 \\
\hline DF & 8 & 6 & 6 & 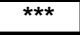 \\
\hline ES & 10 & 9 & 9 & $\star \star \star \star$ \\
\hline GO & 17 & 15 & 15 & $\overline{\star \star \star \star}$ \\
\hline MA & 18 & 17 & 17 & $\overline{\star \star \star \star}$ \\
\hline MG & 53 & 54 & 53 & * \\
\hline MS & 8 & 6 & 6 & $\overline{k \star \star}$ \\
\hline MT & 8 & 7 & 7 & 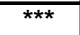 \\
\hline PA & 17 & 18 & 17 & * \\
\hline PB & 12 & 11 & 11 & $\overline{\star \star \star \star *}$ \\
\hline PE & 25 & 24 & 24 & $\star \star \star \star$ \\
\hline PI & 10 & 9 & 9 & 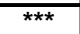 \\
\hline PR & 30 & 29 & 29 & $\star \star \star \star$ \\
\hline RJ & 46 & 44 & 44 & 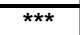 \\
\hline RN & 8 & 8 & 8 & 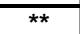 \\
\hline RO & 8 & 4 & 4 & 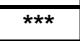 \\
\hline RR & 8 & 1 & 1 & $\star \star \star$ \\
\hline RS & 31 & 31 & 31 & $\star \star \star$ \\
\hline SC & 16 & 16 & 16 & ** \\
\hline SE & 8 & 5 & 5 & $\overline{\star \star \star \star}$ \\
\hline SP & 70 & 112 & 70 & * \\
\hline TO & 8 & 3 & 3 & $\overline{\star \star \star \star}$ \\
\hline
\end{tabular}

Fonte: Dados IBGE, Seção de Documentos Audiovisuais da Câmara dos Deputados (CEDI).

(*) Para os estados sub-representados havia impossibilidade de ajustes

(**) Não houve necessidade de ajuste

(***) Para os estados sobre-representados as bancadas forma ajustadas

Foram simuladas 455 votações nominais ocorridas no Plenário em sessões da Câmara dos Deputados durante a $51^{\text {a }}$ Legislatura. Utiliza-se o termo votação para denominar qualquer deliberação feita em Plenário, podendo uma dada proposição ter associada a si várias votações.

Apenas em uma única votação, do Destaque de Votação em Separado do PSB/PC do B referente ao inciso II do artigo $85^{\circ}\left(\operatorname{artigo} 4^{\circ}\right.$ ) da Proposta de Emenda a Constituição no 407/2001, que acrescentava artigos ao Ato das Disposições Constitucionais Transitórias prorrogando a vigência da CPMF até 31 de dezembro de 2004, a simulação acusou um resultado diverso ao efetivamente ocorrido. O DVS tratava de dar isenção da CPMF às operações nas Bolsas de Valores, o que, sob o ponto de vista de alguns parlamentares, seria uma forma de dar a essas operações imunidade tributária em detrimento de outras aplicações financeiras.

O dispositivo foi mantido com o seguinte resultado: 311 votos favoráveis, 99 contrários e 1 abstenção. Pela simulação, o resultado seria : 279 votos favoráveis, 92 contrários e 1 abstenção. 
Apesar do Plenário manter padrão de comportamento semelhante, não foi alcançado o quorum de 308 votos para aprovação. Como na votação original a matéria foi aprovada pela margem estreita de 3 votos, considera-se que a causa primordial na alteração do resultado foi o decréscimo de $10 \%$ aplicado aos votantes para proceder à simulação, descartando qualquer influência que a distorção ora verificada na Casa tenha sobre a aprovação ou rejeição de qualquer matéria.

\section{Análise dos Resultados}

A fim de justificar a manutenção dos resultados, procedeu-se, após os ajustes, a uma comparação dos dois cenários pelo critério de divisão política. Distribuíram-se as bancadas politicamente a partir de classificação feita em Limongi (2005) que relacionou os partidos que formaram a coalizão de apoio ao Governo Fernando Henrique Cardoso durante a legislatura analisada. Adicionalmente, baseado nos mesmos critérios de divisão, montou-se quadro semelhante, desta vez com a configuração suposta caso se distribuísse proporcionalmente as vagas da Casa. O resultando está exposto a seguir.

Tabela 3 - Composição da Casa na $51^{\text {a }}$ Legislatura

\begin{tabular}{|c|c|c|c|}
\hline Partido & Orientacão & Bancada Oficial & Bancada Simulada \\
\hline PFL & Governo & 95 & 88 \\
\hline PL & Governo & 22 & 18 \\
\hline $\mathrm{PMDB}$ & Governo & 83 & 77 \\
\hline $\mathrm{PP}$ & Governo & 52 & 48 \\
\hline PSDB & Governo & 91 & 79 \\
\hline PSL & Governo & 5 & 5 \\
\hline PST & Governo & 4 & 4 \\
\hline $\mathrm{PTB}$ & Governo & 41 & 36 \\
\hline Total Governo & & 393 & 355 \\
\hline $\mathrm{PCdoB}$ & Oposicão & 7 & 7 \\
\hline $\mathrm{PDT}$ & Oposicão & 15 & 15 \\
\hline $\mathrm{PHS}$ & Oposicão & 1 & 1 \\
\hline PPS & Oposicão & 15 & 14 \\
\hline PSB & Oposicão & 16 & 12 \\
\hline $\mathrm{PT}$ & Oposicão & 61 & 57 \\
\hline PTN & Oposicão & 1 & 1 \\
\hline PV & Oposicão & 1 & 1 \\
\hline S.Part. & Oposicão & 3 & 3 \\
\hline Total Oposicão & Onosicão & 120 & 111 \\
\hline
\end{tabular}

Fonte para simulação: Dados IBGE, Seção de Documentos Audiovisuais do Centro de Documentação e Informação da Câmara dos Deputados (CEDI).

Caso sejam desconsideradas as movimentações parlamentares e seja utilizado o critério de filiação partidária no momento da posse, os dados sugerem que a distribuição política entre votos de partidos da coalizão governamental e oposição praticamente não variou após a adequação proposta. A proporção de representantes 
alinhados ao Governo variou de $77 \%$ para $76 \%$ na simulação.

Além disso, utilizou-se uma segunda abordagem para análise das votações ocorridas na $51^{\text {a }}$ Legislatura. Verificou-se o padrão de voto dos partidos oposicionistas considerando-se a orientação de voto dada pela Liderança do Governo. Verificou-se que, nas votações analisadas, o Governo indicou os seguintes votos:

Tabela 4 - Indicação de voto da Liderança do Governo

\begin{tabular}{|c|c|}
\hline Orientacão do Governo & Número de Votacões \\
\hline Sim & 218 \\
\hline Não & 115 \\
\hline Abstencão & 2 \\
\hline Obstrucão & 7 \\
\hline Liberado & 112 \\
\hline
\end{tabular}

Fonte : Coordenação do Sistema Eletrônico de Votação do Centro de Informática da Câmara dos Deputados (COSEV-CENIN)

Nessas votações, a média de deputados oposicionistas que acompanharam o governo foi de $50,26 \%$. Caso se delimite essa amostra aos deputados oposicionistas que representam estados sobre-representados na legislatura (vide Tabela 2), esse número seria $50,35 \%$, uma diferença marginal em relação ao cenário anterior.

\section{Conclusão}

Ao se proceder a uma análise mais acurada sobre a questão, delimitando o escopo à $51^{\text {a }}$ Legislatura e descartando-se fatores subjetivos inerentes à política e seus atores, não se verificou, quando do exame dos resultados das votações em Plenário, dado relevante que venha a indicar que os representantes trazidos à Casa, mesmo por meio de distorção questionada por muitos, tenham tido participação determinante, no que tange aos votos dados, para alterar a direção das deliberações tomadas.

Adicionalmente, para o período analisado, não se inferiu um padrão de comportamento perceptível que sugerisse qualquer distinção entre o comportamento presumido do grupo em relação às demandas do Executivo, sugerindo a inexistência de influência efetiva da sobre-representação de regiões nas deliberações da Câmara dos Deputados.

\section{Referências}

BACKES, Ana Luiza. Democracia e sobre-representação de regiões: o papel do senado. Brasília: 1998, $149 \mathrm{f}$.

BRITTO, Luiz Navarro de. A Representação Proporcional. Revista Brasileira de Estudos Políticos, n. ${ }^{\circ} 19,1965$ 
CARVALHO, Nelson Rojas. Concentração e dispersão de voto: um estudo da geografia eleitoral e dos padrões de competição política no Brasil. Rio de Janeiro, 1996. Dissertação (Mestrado em Ciência Política). IUPERJ.

DILLON SOARES, Gláucio Ary. Desigualdades Eleitorais no Brasil. Revista de Ciência Política, n. ${ }^{\circ} 7,1973$.

DILLON SOARES, Gláucio Ary. Colégio Eleitoral, convenções partidárias e eleições diretas. Ed. Vozes, Petrópolis, 1984.

GIBSON, Edward L. Federalismo realocativo: sobre-representação legislativa e gastos públicos no hemisfério ocidental. In: Opinião pública, v.9, n.1, p.98-123, abr. 2003.

IBGE. Estatísticas do Século $X X$ : Estatísticas populacionais, sociais, políticas e culturais. Base de Dados. Disponível em: < http://www.IBGE.GOV.BR/>.

KATZ, Ellis. Asymetrical aspects of american federalism. Trabalho apresentado no $6^{\circ}$ Encontro Nacional de Direito Constitucional, São Paulo, Brasil, set. 1997.

LAMOUNIER, Bolívar. A representação proporcional no Brasil : mapeamento de um debate. In:

Revista de cultura \& política, n.7, p.5-42, 1982.

LAMOUNIER, Bolívar. Forma de governo e representação três estudos. São Paulo: Idesp, 1987.

LIMONGI, Fernando e FIGUEIREDO, Angelina. O Sistema Político Brasileiro entre mitos e fatos. Revista do Movimento do Ministério Público Democrático, n. 6, p.21-23, ago. 2005. Disponível em http://www.ifb.com.br/arquivos/Limongi.pdf.

NOGUEIRA, Octaciano. Representação Proporcional e Distorção Eleitoral. Estudos Eleitorais, vol. 1, n. ${ }^{\circ}$ 1, p. 137-156, Tribunal Superior Eleitoral, 1997.

REALI, Miguel, 1910-. O sistema de Representação Proporcional e o Regime Presidencial Brasileiro. In: Revista Brasileira de Estudos Políticos, n.7, p.9, nov. 1959. IN: Estudos eleitorais, v.1, n.1, p.101-135, jan./abr. 1997.

SANTOS, Wanderley Guilherme dos. Crime e Castigo: Partidos e Generais na Política Brasileira. Rio de Janeiro, Ed. Revista dos Tribunais, 1987.

SERRA, José. Eleitores de Primeira e Segunda Classe, Cidadãos Menos Iguais. Estudos Eleitorais, vol. 1, n. ${ }^{\circ}$ 1, p. 157-177, Tribunal Superior Eleitoral, 1997.

SOARES, Márcia Miranda. Luiz Cláudio Lourenço: A Representação Política dos Estados na Federação Brasileira: algumas notas críticas. 2002. Disponível em 〈http://www.cienciapolitica.org.br/encontro/reppol4.3.doc >. Acesso em 11/07/2006.

TSE. Eleições: Resultados e Estatísticas :. Disponível em http://www.tse.gov.br/internet/index.html. Acesso em 30/11/2006. 